\title{
Assessment of nurses' opinion about reporting medication errors: a cross-sectional study
}

\author{
*Udi O.A. ${ }^{1}$, Ogbu B.N. ${ }^{1}$, Chukwuyem N.E. ${ }^{2}$, Ike C.Q. ${ }^{3}$
}

\begin{abstract}
Objectives: Recently, there have been significant efforts through research to evaluate opinions about cause/etiology of non-reporting of medication errors. However, the challenge of defining what constitutes medication errors has raised the concern of whether errors in medication should be reported. The purpose of the study is to assess nurses' opinion about reporting medication errors.
\end{abstract}

Methods: Quantitative-cross-sectional research conducted to investigate nurses' opinion about reporting medication errors. This study was carried out among nurses working in a government hospital in Nigeria. A total of 259 (43.5\%) Registered Nurses were randomly selected as respondents to the study.

Results: Study findings reveals that 195 (75.3\%) of nurses report their incidents of medication errors while $64(24.7 \%)$ of nurses do not report. In addition, $47.7 \%$ of nurses indicated that relationship with their colleagues informed their decision to report medication error. Sadly, $22.1 \%$ of nurses never reported their involvement in medication errors and all, $100 \%$, the nurses unanimously indicated that medication error that led to patient death should be reported.

Conclusion: There's no doubt that patients' health suffer unnecessary risk following medication errors hence, the study finding suggests that cordial relationship among colleagues encourage medication error reporting.

Keywords: Reporting, Medication Errors, Nurses, Assessment

\author{
*Corresponding author \\ UdiO.A. \\ http://orcid.org/0000-0003-0591-1068 \\ Email: oudi@pums.edu.ng \\ ${ }^{1}$ PAMO University of Medical Sciences, Port Harcourt, Rivers State, Nigeria \\ ${ }^{2}$ Edo University, Edo State, Nigeria \\ ${ }^{3}$ Ondo State University of Medical Sciences, Ondo State, Nigeria
}




\title{
Évaluation de l'opinion des infirmières sur le signalement des erreurs de médication: étude transversale
}

\author{
*Udi O.A. ${ }^{1}$, Ogbu B.N. ${ }^{1}$, Chukwuyem N.E. ${ }^{2}$, Ike C.Q. ${ }^{3}$
}

\begin{abstract}
Resume
Objectifs: Des recherches ont été effectuées récemment pour évaluer les opinions sur la cause / l'étiologie de la nondéclaration des erreurs de médication. Cependant, le défi de définir ce qui constitue des erreurs de médication a soulevé la question de savoir si les erreurs de médication doivent être signalées. Le but de cette étude est d'évaluer l'opinion des infirmières sur le signalement des erreurs de médication.
\end{abstract}

Méthodes: Recherche quantitative transversale menée pour examiner l'opinion des infirmières sur le signalement des erreurs de médication. Cette étude a été réalisée auprès d'infirmières travaillant dans un hôpital gouvernemental au Nigéria. Au total, 259 infirmières autorisées $(43,5 \%)$ ont été sélectionnées au hasard en tant que répondants à l'étude.

Résultats: Les résultats de l'étude révèlent que 195 infirmières (75,3\%) ont signalé des erreurs de médication alors que 64 infirmières $(24,7)$ n'en ont pas parlé. De plus, 47,7\% des infirmières ont indiqué que leur relation avec leurs collègues avait influencé leur décision de signaler une erreur de médication. Malheureusement, 22,1\% des infirmières n'ont jamais signalé leur implication dans des erreurs de médication et toutes les infirmières $(100 \%)$ ont unanimement indiqué qu'une erreur de médication ayant entraîné le décès du patient devait être signalée.

Conclusion: il ne fait aucun doute que la santé des patients présente des risques inutiles après des erreurs de médication. Par conséquent, les résultats de l'étude suggèrent que les relations cordiales entre collègues encouragent la notification des erreurs de médication.

Mots-clés: rapports, erreurs de médication, infirmières, évaluation

\author{
*Auteur principal \\ UdiO.A. \\ http://orcid.org/0000-0003-0591-1068 \\ Email: oudi@pums.edu.ng
}

\author{
${ }^{1}$ PAMO University of Medical Sciences, Port Harcourt, Rivers State, Nigeria \\ ${ }^{2}$ Edo University, Edo State, Nigeria \\ ${ }^{3}$ Ondo State University of Medical Sciences, Ondo State, Nigeria
}

Research Journal of Health Sciences subscribed to terms and conditions of Open Access publication. Articles are distributed under the terms of Creative Commons Licence (CC BY-NC-ND 4.0). (http://creativecommons.org/licences/by-nc-nd/4.0).

http://dx.doi.org/10.4314/rejhs.v7i3.10 


\section{INTRODUCTION}

According to Reid-Searl, Moxham, Walker and Happell (1) implementation of medication process needs the cooperation of healthcare professionals involved in medication handling such as physicians, pharmacists and nurses. The starting point in medication process is the physician's decision about the administration of the correct medicine to a patient. However, this process ends with medication administration to patient as well monitoring patient's response to the medicine. Nurses are part of the final stage of medication process and are responsible for administering medication to the patient.

It is recorded that administration of medication requires scientific judgment, knowledge and skills application (2). On each shift, Armitage and Knapman (3) reported that about $40 \%$ of working time is spent by nurses to deal with events related with medicines. Therefore, when a medication error (ME) occurs, nurses as front-line healthcare professionals of the medication process are more likely to be blamed. The National Coordinating Council for Medication Error Reporting and Prevention (4) affirmed that indeed, nurses are at the "sharp end" of this procedure.

According to Evans (5), there are research documentation which recorded the sources or the circumstances that medication errors (MEs) took place. Immediately the factors causing medication errors are identified and detected, it becomes crucial to apply proper measures to prevent medication error and consequently reduction of incidence of medication errors by nurses. Certainly, medication errors have remained a challenge, because the healthcare profession is subject to constant development (technological and pharmaceutical).

Results from a study (6) showed the inconsistency in the definition of medication errors. Without clear definitions, Harding and Petrick (7) concluded that the degree of underreported medication errors can't be fully recognized thereby contributing to the inability to change key aspects of a complex medication delivery system. Mrayyan, et al (8) highlighted that at a number of factors such as medication errors contribute to risk on patient safety. Hence, it is proper to say that "medication error is a factor affecting patient safety". Nurses are active participants in the management of patients' medication although, physicians and pharmacists participate in medication process. It is important to examine medication errors in clinical nursing practice, because it has the potential to harm the patient. Furthermore, the hospital setting and the health workers feel the burden due to medication errors. In as much as the contributing factors to medication errors are already acknowledged, a study (9) added that preventing them is achievable by implementing useful strategies to impede their occurrence.

Karavasiliadou and Athanasakis (6) stated that nurses should often ascertain that previous steps in medication process have been performed correctly and complete the drug administration safely. Cleary-Holdforth and Leufer (10) opined that implementing respective educational strategies is paramount to hindering the appearance of errors in medication or enhancing adequacy in its management since taking for granted that nurses' education is an integral part of their career and the factors contributing to medication errors are acknowledged in several ways. For instance, Blank, et al (11) suggested that interventions rooted in educational content are more valuable. For example, the education and training of nurses through various methods of information delivery, hands on practice and other didactic measures in medication errors' fields (e.g. medication calculation skills, distractions/interruptions, etc) or preventive measures. Furthermore, a study (6) opined that prompt identification of errors before they reach the patient, the understanding of cases and circumstances that cause medication errors and put nurses at risk to commit medication errors are contained in the prevention-focused functions. The utmost aim of such interventions is to improve Nurses' role, make the medication process safe and deliver quality care to the patients.

Administration of medication is one of the hazardous task in nursing care within the hospital environment. This is due to the vulnerability to errors (18). Reporting of ME incidents can ameliorate the safety of patients (19). It is psychologically destabilizing to nurses and harmful to the patient when cases of MEs are executed (20). Across the globe, MEs contribute to patient ill health and subsequent death and are named as one of the foremost five medical errors as categorized by the American Institute of Medicine (8).

A study in Taiwan noted that $10 \%$ of medical litigations were because of MEs and majority of the errors were underreported (21). Without considering the magnitude of MEs incidence, it is challenging to state how obvious 
the concept of MEs is in developing countries because of poor documentation and insufficient error-reporting systems and inadequate research in the area (8).

\section{MATERIALS AND METHODS}

The study is a cross-sectional survey conducted to investigate nurses' opinion about reporting Medication errors. The study setting is a tertiary healthcare institution in Nigeria which commenced operation in 1980. The study was carried out among nurses. A total of 259 (43.5\%) Registered Nurses were selected from the total population (596) of nurses as respondents in the study using consecutive sampling method. Instrument for data collection was a researcherstructured questionnaire with closed-ended questions.

Application seeking for permission to conduct the study was made to the Research Ethics Committee of study setting while informed consent of participants was sought after the participants were informed about the nature of the study and how confidentiality and anonymity of participants will be guaranteed.

Data collection commenced with daily distribution and retrieval of self-administered questionnaire from one unit of the hospital to the other until all questionnaires were recovered. Data collection spanned through a period of 3 weeks. Participation was voluntary. The questionnaires completely responded to by the nurses were returned resulting to high response rate of $100 \%$. Collected data was analysed with Statistical Package for the Social Sciences (SPSS) Version 21. Data was presented in percentage and frequency table and charts.

\section{RESULTS}

Table 1 reveals that $195(75.3 \%)$ of nurses report when they are involved in medication errors while 64 (24.7\%) of nurses do not. Out of $195(75.3 \%)$ nurses who report medication errors, $61(31.3 \%)$ of nurses indicated that past medication error experiences informed their decision to report medication error, 93 $(47.7 \%)$ of nurses indicated that relationship with their colleagues informed their decision to report medication error, 34 (17.4\%) of nurses indicated that the type of error informed their decision to report medication error, $5(2.6 \%)$ of nurses indicated that medication error reporting as a routine in the facility informed their decision to report medication error.

Figure 1 shows that $22.1 \%$ of nurses never reported their involvement in medication errors, $7.2 \%$ rarely report their involvement in medication error, $50.3 \%$ sometimes report their involvement in medication error, $7.7 \%$ frequently report their involvement in medication error and $12.8 \%$ always report their involvement in medication error.

Data presented in Table 2 shows that out of a total of 259 nurses, $229(88.4 \%)$ indicated that medication error with mild or no adverse effect should be reported while $30(11.6 \%)$ of them indicated that medication error with mild or no adverse effect should not be reported. In addition, all, 259 (100\%) nurses unanimously indicated that medication error that led to patient death should be reported while none of the nurses indicated otherwise.

\section{DISCUSSION}

It is useful to investigate medication error reporting, assess the various indices that connect to reporting of MEs among nurses. Opinions about reporting medication errors may differ hence, this study revealed nurses' opinion about reporting incidents of medication errors. Regarding reporting of medication errors, investigations conducted shows that the rate of reporting medication errors varies at different settings. The study findings suggest that more than half, $75.3 \%(n=259)$, of the respondents report medication errors. This is consistent with a study (12) with slightly similar sample size that recorded $57.4 \%(n=288)$ as the proportion of medication error reporting among nurses. Another study (13) claimed that 55\% of nurses reported their medication errors while Zaree, et al (14) noted that a lesser proportion, $29 \%$, of its study participating nurses reported medication errors in 2015. The proportion of respondents who are unlikely to make MEs' reports in their healthcare institution calls for concern although the number contradicts the report by another study (15) which affirmed that majority of the study participants were not obliged to report MEs in their place of work. Considering the findings and the importance of patient safety, it's imperative that $\mathrm{ME}$ incidents are reported to the appropriate health and hospital management body and that reporting incidents of MEs can serve as a means of preventing future drug errors.

Results of the study revealed that a larger proportion of the study participants report incidents of medication errors due to their relationship with their colleagues. This is similar to a study (16) that opined a proper relationship among members of medical team will reduce medication errors and increase the reporting of 
potential errors. On the other hand, a few of the respondents, $2.6 \%$, report MEs incidents as a routine in the facility where they work. This is in contrast to the study published in 2018 (12) which documented factors associated with medication error reporting and found the relationship between socio-demographics (sex, marital status working area) and reporting of medication errors. In addition, our finding reported that past medication error experiences informed respondents' decision to report incidents of medication errors. This is in agreement with Abebaw, et al (12) which concluded that having a medication error experience was found to be an important determinant of medication error reporting.

Reporting medication errors can be a preventive form of intervention and form part of relevant strategy that must be implemented against future occurrence of medication errors. Findings of this study revealed that more than half of the respondents sometimes report medication error while a few of them always report medication error incidents. This is slightly congruent to a study (17) which investigated frequency of formal and informal reporting of medication errors of nurses. However, their study differ from the study under review in that it determined MEs reporting frequency in relation to various forms of MEs and shows that the least frequency of informal reporting of MEs among nurses belongs to not giving the prescribed medication to patients, giving patients sublingual or chewable medications by mouth. Giving the study findings, reporting MEs may be identified as crucial but special medication errors' field that should be part of educational strategy to hinder occurrence of MEs.

Irrespective of the Nurses' position in medication errors (the source of the error, a contributor, an observer), healthcare institutions depend on them as front-line staff to identify and report medication errors. Assessing nurses' opinion about reporting medication errors with mild or no adverse effect, $88.4 \%$ indicated in affirmation that such errors should be reported. However, it is worrisome to note that there are others, $11.6 \%$, who deem it less important to report medication errors with mild or no adverse effect. Participants' opinion about reporting medication errors that led to patient death indicates an unbiased support that respondents are more likely to report patient death, a form of adverse drug incidents, experienced in their practices if a drug error occurred. There seems to be no specified literature to support these findings hence, the need to conduct surveys addressing issues of reporting adverse drug incidents.

\section{CONCLUSION}

The study noted that relationship with my colleagues informed nurses' decision to report MEs while MEs reporting as a routine in the hospital, had less impact on their decision to make report of MEs. Most of the respondents were of the opinion that MEs with mild or no adverse effect should be reported while a few had contrary opinion. Hence, the need for thorough education of nurses and other Healthcare workers on the implication of non-reporting of MEs.

There's no doubt that patients' health suffer unnecessary risk following medication errors. A lot can be done to minimise incidence of medication errors and halt situations, which "permit" it. In the end, it is difficult to achieve the goal of medication errors elimination, rather decreasing its rate can be accomplished by giving the required attention to contributory factors, implementing effective medication errors reporting media and applying the suitable medication error preventive measures. Emphasis should be placed on the need for continuous education and training of nurses about MEs and reporting errors related to medications.

The study failed to investigate types of MEs whose related errors were not reported, determine the cause of non-reporting of MEs by $24.7 \%$ who indicated they do not report MEs incidents. In addition, the study was deficit at comparing ME report to demographic.

\section{Ethics Approval and Consent to Participate}

The researcher obtained an ethical approval of this research study from the Research Ethics Review Committee of the study setting after the submission and proper scrutiny of copies of the research instrument, chapter one, two and three of the study used by the research ethical committee as a working guide. In addition, administrative approvals from the participating Department (Nursing) were obtained. Before the actual study, verbal informed consent to participate was obtained from the participants because the researcher was not informed by the Ethics Review Committee about its process of obtaining consent from the participants neither was there any approval or disapproval of verbal informed consent. The objectives of the study were explained to the respondents while their participation was voluntary and anonymous to obtain their consent. Respondents were assured of their accessibility to the result of the study. 
Acknowledgement: The authors wish to thank the respondents for their participation in the study.

Conflicts of interest: The authors declare no conflict of interest.

\section{REFERENCES}

1. Reid-Searl K, Moxham L, Walker S, Happell B. Shifting supervision: implications for safe administration of medication by nursing students. Journal of Clinical Nursing. 2008; 17(20): 2750 2757.

2. Nursing and Midwifery Council, UK. Standards for Medicines Management. 2010. Accessed on March $15^{\text {th }}$ from: http://www.nmcuk.org/Documents/NMC-Publications/NMCStandards-for-medicines-management.pdf.

3. Armitage G, Knapman H. Adverse events in drug administration: a literature review. Journal of Nursing Management. 2003; 11(2): 130-140.

4. USA National Coordinating Council for Medication Error Reporting and Prevention. Reducing Medication Errors Associated with Atrisk Behaviors by Healthcare Professionals. 2007; Accessed on March $19^{\text {th }}$ from: http://www.nccmerp.org/council/council200706-08.html.

5. Evans J. Prevalence, risk factors, consequences and strategies for reducing medication errors in Australian hospitals: a literature review. Contemporary Nurse. 2009; 31(2): 176-189.

6. Karavasiliadou S, Athanasakis E. An inside look into the factors contributing to medication errors in the clinical nursing practice. Health Science Journal. 2014; 8(1): 34-37

7. Harding L, Petrick T. Nursing student medication errors: a retrospective review. Journal of Nursing Education. 2008; 47:43-47.

8. Mrayyan MT, Shishani K, Al-Faouri I. Rate, causes and reporting of medication errors in Jordan: nurses' perspectives. Journal of Nursing Management. 2007; 15(6): 659-670.

9. Choo J, Hutchinson A, Bucknall T. Nurses' role in medication safety. Journal of Nursing Management. 2010; 18(7): 853-861.

10. Cleary-Holdforth J, Leufer T. The strategic role of education in the prevention of medication errors in nursing: part 2. Nurse Educator Practitioner 2013; 13(3): 217-220.

11. Blank FS, Tobin J, Macomber S, Jaouen M, Dinoia M, Visintainer P. A "back to basics" approach to reduce ED medication errors. Journal of Emergency Nursing 2011; 37(2): 141-147.

12. Abebaw J, Mignote $H$, Anteneh $M$, Tesfaye $D$ and Mohammed H. Proportion of medication error reporting and associated factors among nurses: a cross sectional study. BMC Nursing. 2018; 17:9

13. Fathi A, Hajizadeh M, Moradi K, Zandian H, Dezhkameh M, Kazemzadeh S \& Rezaei S. Medication errors among nurses in teaching hospitals in the West of Iran: what we need to know about prevalence, types and barriers to reporting. Epidemiology and Health. 2017; 39. Doi: 10.4178/epih.e2017022

14. Zaree TY, Nazari J, Jafarabadi MA, Alinia T. Impact of Psychosocial Factors on Occurrence of Medication Errors among Tehran Public Hospitals Nurses by Evaluating the Balance between Effort and Reward. Safety and Health at Work. 2018;9 (2018):447-453

15. Abdel-Latif MMM. Knowledge of health professionals about medication errors in hospitals. Journal of Basic Clinical Pharmacology. 2016;7: 87-92

16. Mansouri A, Ahmadvand A, Hadjibabaie M, Kargar M, Javadi M and Gholami K. 2013. Types and Severity of Medication Errors in Iran; a review of the current literature. Daru. 2013;21(1):49. DOI:10.1186/20082231-21-49

17. Mostafaei, D., Barati Marnani, A., Mosavi Esfahani, H., Estebsari, F., Shahzaidi, S., Jamshidi, E., \& Aghamiri, S. S. Medication errors of nurses and factors in refusal to report medication errors among nurses in a teaching medical center of iran in 2012. Iranian Red Crescent medical journal. 2014; 16(10), e16600. doi:10.5812/ircmj. 16600

18. Evans, SM. Attitudes and barriers to incident reporting: a collaborative hospital study. Qual Saf Health Care. 2006;15(1):39-43. doi: 10.1136/qshc.2004.012559.

19. Gaal S, Verstappen W, Wensing M. Patient safety in primary care: a survey of general practitioners in the Netherlands. BMC Health Serv Res. 2010;10(1):21. doi: 10.1186/1472-6963-10-21

20. Ulanimo VM, O'Leary-Kelley C, Connolly PM. Nurses' perceptions of causes of medication errors and barriers to reporting. J Nurs Care Qual. 2007;22(1):28-33. doi: 10.1097/00001786200701000-00007.

21. Chiang H-Y, Pepper GA. Barriers to nurses' reporting of medication administration errors in Taiwan. J Nurs Scholarsh. 2006;38(4):392-399. doi: 10.1111/j.1547-5069.2006.00133.x. 
Table 1: Showing respondents who report when involved in medication errors

\begin{tabular}{|c|c|c|}
\hline Parameters & Options & Nurses $(\%) n=259$ \\
\hline \multirow{4}{*}{$\begin{array}{l}\text { Did you report when you were } \\
\text { involved in medication errors? }\end{array}$} & Yes & $195(75.3)$ \\
\hline & No & $64(24.7)$ \\
\hline & Total & $259(100)$ \\
\hline & & $\mathrm{n}=195$ \\
\hline \multirow[t]{4}{*}{$\begin{array}{l}\text { What informed your decision to } \\
\text { report medication error? }\end{array}$} & $\begin{array}{l}\text { Past medication error } \\
\text { experiences }\end{array}$ & $61(31.3)$ \\
\hline & $\begin{array}{l}\text { Relationship with my } \\
\text { colleagues }\end{array}$ & $93(47.7)$ \\
\hline & Type of error & $34(17.4)$ \\
\hline & $\begin{array}{l}\text { ME reporting as a } \\
\text { routine in the facility }\end{array}$ & $5(2.6)$ \\
\hline
\end{tabular}

Table 2: Respondents' opinion about reporting medication error

\begin{tabular}{lll}
\hline Parameters & Options & Nurses (\%) n= 259 \\
\hline $\begin{array}{l}\text { In your own opinion should medication } \\
\text { error with mild or no adverse effect be }\end{array}$ & Yo & $229(88.4)$ \\
$\begin{array}{l}\text { reported? } \\
\text { Total }\end{array}$ & $259(11.6)$ \\
$\begin{array}{l}\text { In your own opinion should medication } \\
\text { errors that led to patient death be }\end{array}$ & Yes & $259(100)$ \\
\begin{tabular}{l} 
reported? \\
\hline
\end{tabular} & Total & $0(0)$ \\
\hline
\end{tabular}

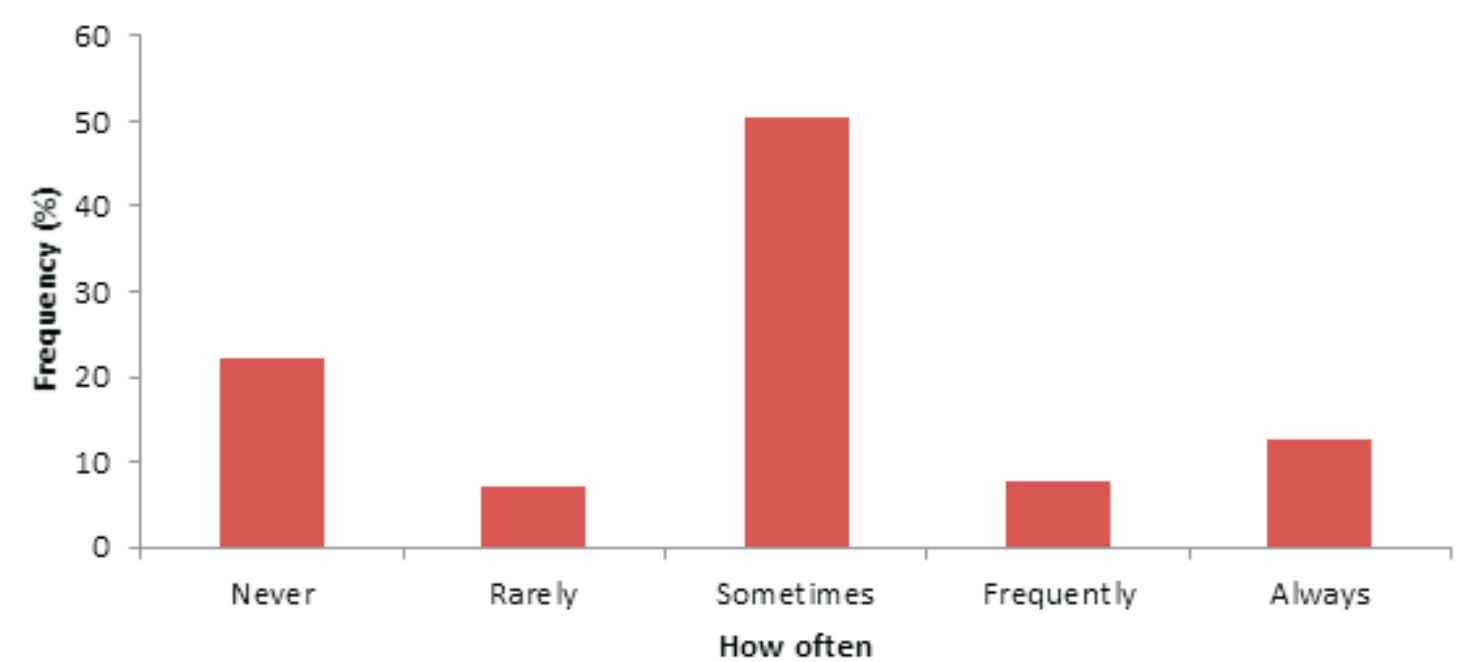

Figure 1: Showing how often respondents who were involved in medication errors report incidents of medication errors 